\title{
How Important is the "Time Horizon"?: An Investigation of Financial Well-Being: An Abstract
}

\author{
Heejung Park
}

\begin{abstract}
Consumer financial well-being is one of the important research areas in marketing (Burroughs and Rindfleisch 2002). Some of the financial products are related to wealth accumulation (Poterba 2000). However, some of the financial products are related to prepare untimely financial risk (Tapiero 2004). Managing mortality risk by purchasing a life insurance policy is important for the consumers in terms of preventing survivors from the financial hardship that eventually erodes family happiness (Dahl and Møller 2006). Previous research has explored the factors that influence the demand for life insurance; however, little effort has focused on the effect of the financial planning time horizon which is crucial to develop an effective strategic plan (Zellweger 2007). Therefore, the purpose of this paper is to examine financial planning time horizon influenced the financial well-being and to investigate the correlations between the amount of life insurance purchased, subjectively reported financial planning time horizon, and numerous financial characteristics that suggests a direction forward in terms of consumer financial well-being as a macro-level goal. As financial counselor and policy maker, it is our mission that longer planning time horizon would be helpful to achieve quality of life for the financial well-being. These findings suggest that individuals perceive liquid assets and credit as an additional safety net rather than a substitute for insurance. Many of financially vulnerable consumers are not purchasing financial products optimal for the purposes. In other words, consumers having a long-term time horizon could both purchase insurance and maintain financial assets or request higher borrowing limits. Consumers with long time planning horizon are likely to have diverse types of financial products as well as higher amount of net worth. The findings indicate that financial education or financial counseling focusing on longer planning time horizon would be helpful for the adequacy of life insurance purchases.
\end{abstract}

References Available Upon Request

H. Park $(\bowtie)$

University of Wyoming, Laramie, WY, USA

e-mail: hpark5@uwyo.edu

(C) Academy of Marketing Science 2019 